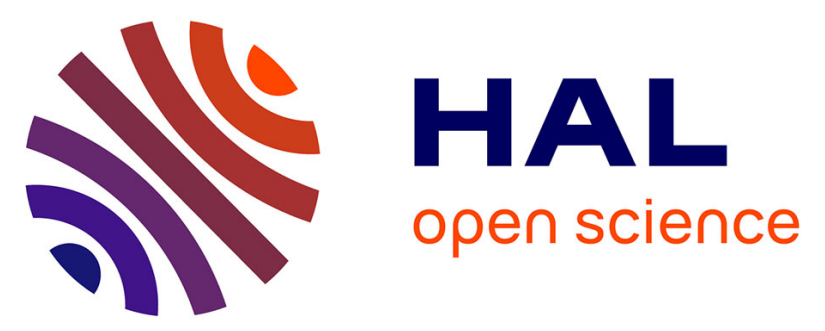

\title{
Stable Integration of Power Electronics-Based DG Links to the Utility Grid with Interfacing Impedance Uncertainties
}

S. Kazem Hoseini, Edris Pouresmaeil, Jafar Adabi, João S. Catalão

\section{- To cite this version:}

S. Kazem Hoseini, Edris Pouresmaeil, Jafar Adabi, João S. Catalão. Stable Integration of Power Electronics-Based DG Links to the Utility Grid with Interfacing Impedance Uncertainties. 6th Doctoral Conference on Computing, Electrical and Industrial Systems (DoCEIS), Apr 2015, Costa de Caparica, Portugal. pp.502-511, 10.1007/978-3-319-16766-4_54 . hal-01343525

\section{HAL Id: hal-01343525 \\ https://hal.inria.fr/hal-01343525}

Submitted on 8 Jul 2016

HAL is a multi-disciplinary open access archive for the deposit and dissemination of scientific research documents, whether they are published or not. The documents may come from teaching and research institutions in France or abroad, or from public or private research centers.
L'archive ouverte pluridisciplinaire HAL, est destinée au dépôt et à la diffusion de documents scientifiques de niveau recherche, publiés ou non, émanant des établissements d'enseignement et de recherche français ou étrangers, des laboratoires publics ou privés.

\section{(c)(1)}

Distributed under a Creative Commons Attribution| 4.0 International License 


\title{
Stable Integration of Power Electronics-Based DG Links to the Utility Grid with Interfacing Impedance Uncertainties
}

\author{
S. Kazem Hoseini ${ }^{1}$, Edris Pouresmaeil ${ }^{2}$, Jafar Adabi ${ }^{1}$ and João P. S. Catalão ${ }^{3}$ \\ ${ }^{1}$ Faculty of Electrical and Computer Engineering, Babol (Noshirvani) \\ University of Technology, PO Box 484, Babol, Iran \\ ${ }^{2}$ Centre for Energy Informatics, University of Southern Denmark (SDU), \\ Odense, Denmark \\ ${ }^{3}$ Univ. Beira Interior, Covilhã, INESC-ID and IST, Univ. Lisbon, \\ Lisbon, Portugal \\ catalao@ubi.pt
}

\begin{abstract}
For the integration of distributed generation (DG) units to the utility grid, voltage source converter (VSC) is the key technology. In order to realize high quality power injection, different control techniques have been adopted. However, the converter-based DG interface is subject to inevitable uncertainties, which adversely influence the performance of the controller. The interfacing impedance seen by the VSC may considerably vary in real distribution networks. It can be observed that the stability of the DG interface is highly sensitive to the impacts of interfacing impedance changes so that the controller cannot inject appropriate currents. To deal with the instability problem, this paper proposes an enhanced fractional order active sliding mode control scheme for integration of DG units to the utility grid, which is much less sensitive to interfacing impedance variations. A fractional sliding surface which demonstrates the desired dynamics of the system is developed and then the controller is designed in two phases: sliding phase and reaching phase to keep the control loop stable. The proposed controller takes a role to provide high quality power injection and ensures precise current tracking and fast response despite uncertainties. Theoretical analyses and simulation results are verified to study the performance and feasibility of the proposed control scheme.
\end{abstract}

Keywords: Voltage Source Converter; Distributed Generation; Interfacing Impedance; Fractional Order Control; Active Sliding Mode Control.

\section{Introduction}

The power network is experiencing structural changes due to increasing concerns about greenhouse gas emissions, energy cost, and security of conventional power generations as more distributed generations (DGs) are integrated to the utility grid [1]. These DG technologies are mainly used to deliver clean energy from renewable energy sources such as solar power, wind power, micro turbine generation plants and fuel cell plants, through power electronic voltage source converters (VSCs) [2].

Stable operation of the control loop in DG system is an important aspect; an instable control loop cannot inject desired power from DG source to the grid. The interfacing impedance seen by the VSC may noticeably change depending on the configuration of the utility grid (as DG units are commonly installed in weak grids), output filter design, and grid synchronization techniques. Also some phenomena such 
as cable overload, temperature effect, and saturation often further aggravate the problem.

Uncertainties in the impedance seen by the VSC leads to instability in the control of DG interfacing system since the stability is so sensitive to the interfacing impedance variations. As a result of instable controller, the DG system cannot inject the expected currents or persistent oscillations may exist in the injected currents. Hence, it seems crucial to design a control structure for the DG system, which is insensitive to the variations of interfacing impedance.

Several control methods and studies have been reported for integration of DG sources into the power grid, however, few works have addressed instability problems of interfaced converters in DG technology. Influence of grid impedance on current control loop have been investigated in [3] and a control technique based on adjusting the controller gain was proposed to stabilize interfaced VSC; however, it needs problematic online measurement of interfacing impedance; moreover, changing controller gain may deteriorate other capabilities such as disturbance rejection. An adaptive grid-voltage sensorless control method has been presented in [4] for converter-based DG units, which needs an additional interfacing parameter estimator in a parallel structure to deal with the stability problem. Reference [5] proposed a model reference adaptive control to connect DG units to utility grid through a LCL filter; nevertheless, it uses converter output current as the feedback signal to the controller, which may result in the resonance of the grid current due to the interaction of converter output harmonic current and the resonant circuit formed by the grid inductor and filter capacitor. An impedance-based stability criterion has been verified in [6], which discusses the condition in which a grid-connected converter is stable, but it does not present a proper control solution for the instability problem. Effects of grid impedance variations on the stability of the interfaced converter have been investigated in [7]. It has been demonstrated that when either the inductance of the grid increases or the inductance and resistance of the grid increase together, the system stability is adversely affected. Also, [7] proposes an $\mathrm{H} \infty$ controller to deal with the instability problem; however, its implementation and obtaining weightingfunctions in such systems are very hard.

Hence, an effective control method is proposed in this paper, which combines fractional order control (FOC) with an active sliding mode control (ASMC). FOC, which is the use of non-integer order derivatives and integrals, has been realized as an alternative scheme for solving control problems [8,9]. Applying the notion of fractional order for managing control problems is a step closer to the practical situations since the real world processes are mostly fractional. Some models of fractional order and fractional calculus have been developed to solve different control problems [10,11]. Sliding mode control is a particular type of variable structure control systems designed to drive and then maintain the system states within a close neighborhood of the decision rule, and is well-known for its robustness to parameter variations and disturbances $[12,13]$. Therefore, combining fractional order approaches together with sliding mode control has attracted significant interest [14-16].

The objective of this study is to extend a fractional order active sliding mode controller $\left(\mathrm{F}_{\mathrm{r}} \mathrm{ASMC}\right)$ to the current control of a grid-connected three-phase VSC for possessing small steady-state tracking error and fast response of the grid current while maintaining the system insensitive to interfacing impedance variations. In this control method, the system states are limited to lie on the fractional sliding surface where the dynamics of the system are only specified by the dynamics of the switching surface. The system is invariant in the control design, and the motion of the states trajectory is 
much less sensitive to disturbances and parameter variations. The control method is easy to implement and only needs nominal values of model parameters.

\section{Contribution to Cloud-based Engineering Systems}

Over the past two decades, declines in the costs of small-scale power generations increases in the reliability needs of many customers, and the partial deregulation of electricity markets have made DG technology more attractive to businesses and households as a supplement to utility-supplied power. Moreover, the environmental advantages can also be considered as a key-driving element accelerating the development of DG technology in power system. However, the increasing numbers of DG units in power system require new and intelligent control techniques for the operation and management of electric networks in order to maintain or even to improve the power supply reliability and quality in the future. As a consequence, DG system can be considered as a cloud-based system, consisting of an intelligent control technique for integration of DG sources to the power grid. This cloud-based aspect of energy technology will concentrate on several issues in design of future power grids based on Smart Grids technology during the presence and cooperation of suitable energy storage devices in the distribution grid. The main goal in this research area is design of a control technique for integration of DG sources into the power grid. In the proposed model, load behavioral patterns can be monitored and the huge amount of data can be harvested from utility and load sides. Its processing is being carried out using algorithms established for signal processing. The proposed control technique confirms the role of DG technology in cloud-based energy system by creating a safe operating region for operation of DG units and injection of power from DG sources into the power grid.

\section{Modeling of a Grid-Connected DG Interface}

This section focuses on a three-phase DG model with a current-controlled VSC. To form a grid-connected DG model, the VSC is integrated to the utility grid with an inductive filter and an isolation transformer. The filter is responsible for filtering out the high frequency harmonics generated by VSC switching actions, and the transformer works as an interfacing reactor. Fig. 1 shows the equivalent circuit diagram of the grid-connected DG unit with three-phase two-level VSC. The VSC synthesizes the AC voltage using space vector modulation (SVM) technique with the available DC voltage. Control signals for the SVM are generated from an appropriate controller, and switching pulses are applied to the VSC switches for power injection from DG source into the power grid. The utility grid is modeled as a three-phase AC source with internal impedance using Thevenin's Theorem. $Z=R+j \omega L$ is the equivalent interfacing impedance seen by the VSC; $i_{x}$ is the converter output current; $v_{g x}$ is the grid voltage; and $i_{d c}$ is the input DC current $(x=a, b$ and $c)$. 


\subsection{Dynamic Analysis of the Proposed Model}

To inject high quality power to the utility grid, a current control technique is usually adopted to form the output voltage so that minimum current error is achieved. A VSC controls the magnitude and frequency of the output voltage. The output voltage at each leg of the VSC can be expressed as

$$
v_{x N}=D_{x N} \cdot v_{d c}
$$

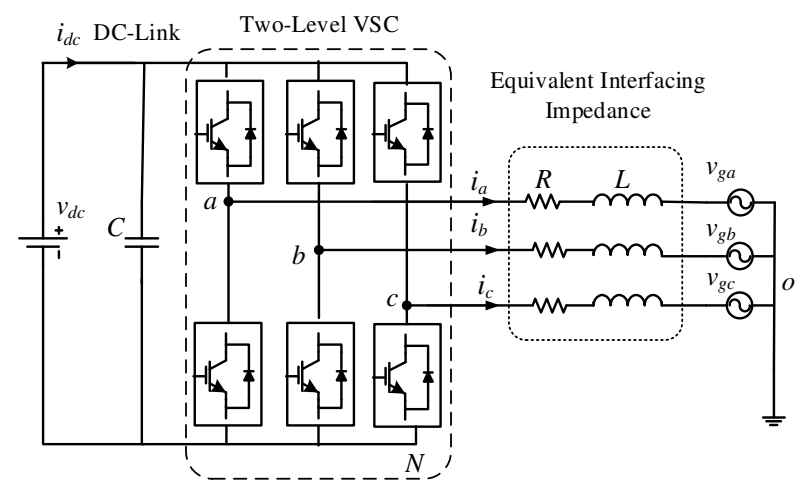

Fig. 1. Equivalent circuit diagram of a generic grid-connected DG unit using three-phase VSC.

where $v_{x N}$ is the converter output leg voltage, and the switching variable $D_{x N}$ determines the switching state of interfaced converter, and can be defined as 1 or 0 when the upper (or lower) switch of the leg is switched on or off. Dynamic equations of the proposed model can be calculated by applying Kirchhoff's law in AC-side of the interfaced converter as,

$$
L \frac{d i_{x}}{d t}+R i_{x}-v_{x o}+v_{g x}=0
$$

where $v_{x o}$ is the converter output phase voltage. By defining the switching state function of the VSC as,

$$
U_{x}=\left(D_{x N}-\frac{1}{3} \sum_{x=a}^{b, c} D_{x N}\right)
$$

and substituting (3) in (2), the dynamic equations of the proposed model can be rewritten as,

$$
L \frac{d i_{x}}{d t}+R i_{x}-U_{x} v_{d c}+v_{g x}=0
$$




\subsection{Steady-State Analysis of the proposed Model}

In synchronous reference-frame, a rotating reference-frame is utilized so that all fundamental positive sequence alternating variables become DC quantities in $d q 0$ coordinate system; then, objectives of controlling and filtering in the control loop of the system can be achieved easier. By Park transformation matrix, dynamic equations of the proposed model in (4) can transfer into the synchronous reference-frame with angular speed $\omega$ as,

$$
\begin{aligned}
& L \frac{d i_{d}}{d t}-L \omega i_{q}+R i_{d}-U_{d} v_{d c}+v_{g d}=0 \\
& L \frac{d i_{q}}{d t}+L \omega i_{d}+R i_{q}-U_{q} v_{d c}+v_{g q}=0 .
\end{aligned}
$$

It should be mentioned that zero components of line currents and grid voltages are zero since balanced operation and symmetric abc voltages are considered. Substituting time-varying components by the steady-state quantities and forcing time derivatives to zero, the steady-state expressions of the proposed model in equations (5) and (6) can be calculated as,

$$
\begin{gathered}
U_{d s}=\frac{-L \omega i_{\text {qref }}+R i_{d r e f}+v_{g d}}{V^{*}{ }_{d c}} \\
U_{q s}=\frac{L \omega i_{d r e f}+R i_{\text {qref }}}{V^{*}{ }_{d c}} .
\end{gathered}
$$

\section{Proposed FrASMC Design of Integrated DG Model}

The current control structure of a three-phase VSC is the key element in the control design of a converter-based DG system. When the interfacing impedance seen by the VSC becomes highly inductive, the bandwidth of the controller is considerably decreased, which degrades the dynamic performance of the controller [7]. This leads the system to be oscillatory or even unstable. In this section, to deal with the instability problem a $\mathrm{F}_{\mathrm{r}} \mathrm{ASMC}$ is designed for the integration of DG units to the power grid with a three-phase framework. The proposed control scheme has the properties of fast response and small steady-state tracking error of the grid current while keeping the performance of the model insensitive to the interfacing impedance uncertainties.

The current dynamics of the proposed model in the synchronous reference frame (5) and (6) can be represented by the following state-space equations, 


$$
\begin{gathered}
\frac{d i_{z}}{d t}=A i_{z}+B U_{z}+T v_{g z} \\
=\left(A_{o}+\Delta A\right) i_{z}+\left(B_{0}+\Delta B\right) U_{z}+\left(T_{o}+\Delta T\right) v_{g z} \\
=A_{o} i_{z}+B_{o} U_{z}+T_{o} v_{g z}+r,
\end{gathered}
$$

$$
\begin{gathered}
\text { where, } i_{z}=\left[\begin{array}{cc}
i_{d} & i_{q}
\end{array}\right]^{T}, \quad U_{z}=\left[\begin{array}{cc}
U_{d} & U_{q}
\end{array}\right]^{T}, \quad v_{g z}=\left[\begin{array}{ll}
v_{g d} & v_{g q}
\end{array}\right]^{T}, A_{o}= \\
\left.\begin{array}{cc}
-R_{o} / L_{o} & \omega \\
-\omega & -R_{o} / L_{o}
\end{array}\right], \quad B_{o}=\left[\begin{array}{cc}
1 / L_{o} & 0 \\
0 & 1 / L_{o}
\end{array}\right] \cdot v_{d c}, \quad T_{o}=\left[\begin{array}{cc}
-1 / L_{o} & 0 \\
0 & -1 / L_{o}
\end{array}\right], \text { and } \\
r=\Delta A i_{z}+\Delta B U_{z}+\Delta T v_{g z}
\end{gathered}
$$

where, $z=d$ and $q ; A, B$ and $T$ are the system matrices; $A_{o}, B_{o}$, and $T_{o}$ represent the nominal values of $A, B$ and $T ; \Delta A, \Delta B$, and $\Delta T$ denote the system parameter variations; and $r$ expresses the lump of uncertainties caused by parameter variations, which is assumed to be bounded by $\delta$,

$$
|r|<\delta,
$$

where, $\delta$ is a specified positive constant.

Considering the described model, the errors dynamics can be defined as follows,

$$
e=x_{\text {ref }}-x=i_{\text {zref }}-i_{z},
$$

where, $i_{\text {zref }}\left(=x_{\text {ref }}\right)$ is the reference current. The objective of the $\mathrm{F}_{\mathrm{r}} \mathrm{ASMC}$ is to design the controller $U_{z}$ such that the model state $\left(x=i_{z}\right)$ precisely tracks the reference output current.

Output of the PID controllers is a linear combination of the input, the integral of the input, and the derivative of the input. Fractional order PID controllers are generalizations of PID controllers. Output of the fractional order PID controllers is a linear combination of the input, a fractional integral of the input, and a fractional derivative of the input. The proportional-integral equation, which defines the fractional order $\mathrm{PI}\left(\mathrm{F}_{\mathrm{r}} \mathrm{PI}\right)[8,14]$ control action can be written as,

$$
v(t)=k_{p} e+k_{i} D^{-\lambda} e
$$

where $k_{p}, k_{i}$, and $\lambda$ are design parameters of the fractional order PI control. If $\lambda$ is 1 , the result is a usual PI (called as integer PI). A switching surface is developed for interfaced converter based on FOC in order to design the $\mathrm{F}_{\mathrm{r}} \mathrm{ASMC}$. In this sense, a fractional form of the linear compensation PI networks is used to achieve fractional sliding surface of the form $\mathrm{PI}^{\lambda}$. Based on the generalized (fractional) $\mathrm{PI}^{\lambda}$ structure, a candidate for fractional sliding surface, which represents a dynamic of desired model can be obtained of the form as,

$$
S=k_{p}\left(x_{r e f}-x\right)+k_{i} D^{-\lambda}\left(x_{r e f}-x\right) ; 0<\lambda<2,
$$


Sliding mode control forces the system state space trajectories to reach the sliding surface in a finite time and to stay on the surface for all future time. The main function of the sliding mode controller is to switch between two different structures of the system so that a new type of system motion (sliding mode) exists on the surface. Therefore, the proposed $\mathrm{F}_{\mathrm{r}}$ ASMC is designed in two phases as,

1- $\quad$ The sliding phase by $S=0$

2- The reaching phase when $S \neq 0$.

In the first phase $(S=0)$, which shows the model operates in desired condition and there are no parameter variations, the active controller can be designed as follows,

$$
U_{z e q}=-B_{o}^{-1}\left(A_{o} x+T_{o} v_{g z}+C_{0} S\right)
$$

where $C_{0}$ is a positive definite matrix for placing poles of the nominal system in its desired values. The active controller works properly when there are no uncertainties; however, the sensitivity of the dominant poles of the current controller is very high to system uncertainties mainly due to parameter variations, which lead to drive harmonic currents through the converter or even the controller may become unstable, i.e. $S \neq 0$. In this phase, in order to drive any states outside the surface to reach the surface in a finite time, a switching control law is developed to construct the $\mathrm{F}_{\mathrm{r}} \mathrm{ASMC}$ as,

$$
U_{z}=U_{z e q}+\gamma \operatorname{sgn}(S)
$$

where $\gamma$ is the switching factor, which can be tuned in order to eliminate the effects of parameter variations. As can be seen from (15) and (16), the nominal values of the model parameters are only required to design the controller.

\section{Simulation Results}

To investigate the performance of the proposed control strategy, the simulation models have been developed under Matlab/Simulink environment.

The rated $\mathrm{rms}$ grid phase voltage is $120 \mathrm{~V}$ at $60 \mathrm{~Hz}$, and the nominal values of interfacing resistance and inductance are $R_{o}=0.2 \Omega$ and $L_{o}=0.1 \mathrm{mH}$, respectively. The dc-link voltage is set to $400 \mathrm{~V}$ and the switching frequency of the VSC is $10 \mathrm{kHz}$. To inject the desired active power $P_{r e f}$ to the grid, $d$-component of the reference current can be obtained as,

$$
i_{\text {dref }}=\frac{2}{3} \frac{P_{\text {ref }}}{v_{g d}}
$$

By setting a zero value for the $q$-component of reference current in the current control loop of DG unit, only active power will be injected by integration of DG sources into the power grid and power factor between the injected current from DG unit and load voltage will be obtained a unity value. The reference active power is set to $3 \mathrm{~kW}$. 
The stability and dynamic response of the DG model will now be analyzed, and the effectiveness of the designed controller will be evaluated and compared with conventional PI synchronous-frame current controller to validate the proposed procedure. To illustrate the effect of interfacing impedance variations on the current controller performance of a VSC-based DG system, the interfacing resistance and inductance seen by the $\operatorname{VSC}(R$ and $L$ ) change from $[R=0.2 \Omega$ and $L=0.1 \mathrm{mH}]$ to $[R=0.5 \Omega$ and $L=0.6 \mathrm{mH}]$ at the instant $t=0.05 \mathrm{~s}$ in simulations.

The performance of the PI current controller under above mentioned condition is depicted in Fig. 2. As can be seen, the current response cannot track the reference current properly when the interfacing impedance changes, which is consequence of the nonrobust PI current controller. Tuning the PI gains can bring the system into stability; however, it leads to degradation of disturbance rejection capability and increase in steady-state tracking error.

Fig. 3 shows the output current of the VSC and utility grid voltage with the proposed $\mathrm{F}_{\mathrm{r}} \mathrm{ASMC}$. It can be observed that the current controller remains stable and injects high quality currents in phase with the utility grid voltage when the interfacing impedance changes. From Fig. 3 the grid-connected power factor is 1 .

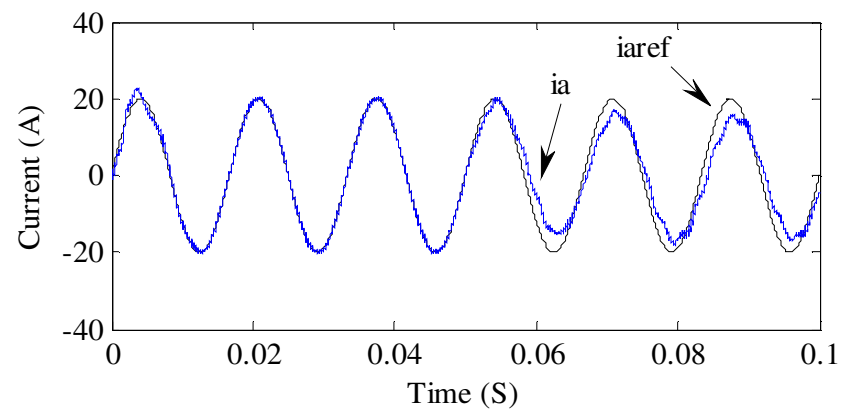

Fig. 2. DG current and its reference with conventional PI controller under interfacing impedance variation at $\mathrm{t}=0.05 \mathrm{~s}$

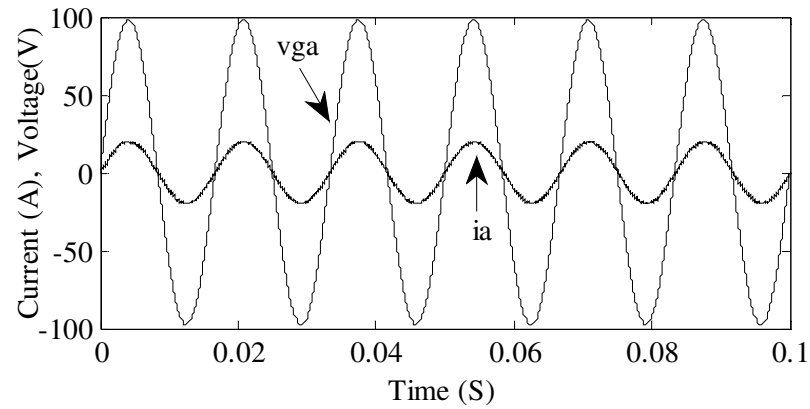

Fig. 3. DG current and grid voltage under interfacing impedance variation at the instant 
$t=0.05 \mathrm{~s}$

By drawing harmonic spectra of current response of conventional PI and proposed $\mathrm{F}_{\mathrm{r}} \mathrm{ASMC}$ before and after interfacing impedance change (with $P_{\text {ref }}=3 \mathrm{~kW}$ ), following results have been observed. THD of output current of the conventional PI current controller before impedance change is $1.08 \%$. However, the THD after impedance change is $6.27 \%$, which does not meet the THD requirement of the IEEE standard 1547 (that is below 5\%) [17]. Furthermore, significant low order harmonics can be observed in the harmonic spectra. THD of VSC output current of proposed $\mathrm{F}_{\mathrm{r}} \mathrm{ASMC}$ before and after impedance change are $0.96 \%$ and $1.12 \%$, respectively, which demonstrates the proposed controller successfully meets the standard requirement and has a better performance than conventional PI.

\section{Conclusions}

DG units are commonly integrated to the utility grid by VSCs for better controllability, reliability, and efficiency. The VSC transfers the generated power to the utility grid using a current controller that has the mission of injecting high quality currents. However, the stability of the current controller is often destroyed by the variations on the interfacing impedance seen by the VSC, such that the system becomes oscillatory or even unstable. In this paper, a $\mathrm{F}_{\mathrm{r}} \mathrm{ASMC}$ has been proposed for integration of DG units to the utility grid. The main aim of the proposed current controller is to deliver the desired power to the grid with low harmonic current, fast response, and high power factor while maintaining the system insensitive to the interfacing impedance variations. To validate the performance of the proposed $\mathrm{F}_{\mathrm{r}} \mathrm{ASMC}$, simulation verification results have been presented and compared with the conventional PI current controller. The results show that high quality current injection is achieved with the proposed $\mathrm{F}_{\mathrm{r}} \mathrm{ASMC}$ for grid integration of VSC-based DG units.

Acknowledgment. This work was supported by FEDER funds (European Union) through COMPETE and by Portuguese funds through FCT, under Projects FCOMP01-0124-FEDER-020282 (Ref. PTDC/EEA-EEL/118519/2010) and PEstOE/EEI/LA0021/2013. Also, the research leading to these results has received funding from the EU Seventh Framework Programme FP7/2007-2013 under grant agreement no. 309048 .

\section{References}

1. Akorede, M. F., Hizam, H., Pouresmaeil, E.: Distributed energy resources and benefits to the environment. Renewable Sustainable Energy Rev, 14(2),724--734 (2010)

2. Blaabjerg, F., Teodorescu, R., Liserre, M., Timbus, V. A.: Overview of control and grid synchronization for distributed power generation systems. IEEE Trans Ind Electron, 53(5), 1398--1409 (2006)

3. Liserre, M., Theodorescu, R., Blaabjerg, F.: Stability of photovoltaic and wind turbine gridconnected inverters for a large set of grid impedance values. IEEE Trans Power Electron, 21(1), 263--272 (2006) 
502 S. K. Hoseini et al.

4. Mohamed, Y. A. I., El-Saadany, E. F., Salama, M. M. A.: Adaptive grid-voltage sensorless control scheme for inverter-based distribution generation. IEEE Trans Energy Convers, 24(3), 683--694 (2009)

5. Mao, X., Ayyanar, R.: An adaptive controller for inverter-interfaced DGs connected to grids with a wide range of unknown impedances. Energy Conversion Congress and Exposition (ECCE). pp. 2871-2877 (2010)

6. Sun, J.: Impedance-based stability criterion for grid-connected inverters. IEEE Trans Power Electron, 20(11), 3075--3078 (2011)

7. Yang, S., Lei, Q., Peng, F. Z., Qian, Z.: A robust control scheme for grid-connected voltagesource inverters. IEEE Trans Ind Electron, 58(1), 202--212 (2011)

8. Podlubny, I.: Fractional-order systems and PI $\lambda \mathrm{D} \mu$ controllers. IEEE Trans Autom Control, 41(1), 208--213 (1999)

9. Valerio, D.: Fractional robust system control. Technical Univ. Lisbon, Ph.D. thesis (2005)

10.Agrawal, O. P.: A general formulation and solution scheme for fractional optimal control problems. Nonlinear Dynamics, 38(1-4), 323--337 (2006)

11.Jelicic, Z. D., Petrovacki, N.: Optimality conditions and a solution scheme for fractional optimal control problems. Struct Multidiscip Opti, 38(6), 571--581 (2009)

12.Bartolini, G., Fridman, L., Pisano, A., Usai, E., (Eds.).: Modern sliding mode control theory: new perspectives and applications. Springer Berlin (2008)

13.Edwards, C., Fossas, Colet. E., Fridman, L., (Eds.).: Advances in variable structure and sliding mode control. Springer Berlin (2006)

14.Hosseinnia, S. H., Tejado, I., Vinagre, B. M., Sierociuk, D.: Boolean-based fractional order SMC for switching systems: application to a DC-DC buck converter. Signal Image and Video Processing, 6(3), 445--451 (2012)

15.Pisano, A., Rapaic, M. R., Jelicic, Z. D., Usai, E.: Sliding mode control approaches to the robust regulation of linear multivariable fractional-order systems. Int J Robust Nonlinear Control, 20(18), 2045--2056 (2010)

16.Efe, M. O.: Fractional order sliding mode control with reaching law approach. Turk J Electr Eng Comput Sci, 18(5), 731--747 (2010)

17.IEEE standard for interconnecting distributed resources with electric power systems, IEEE standard 1547-2003, Jul. 2003. 